Jan., Feb., Mar., 1953

\title{
The Provincial Museum
}

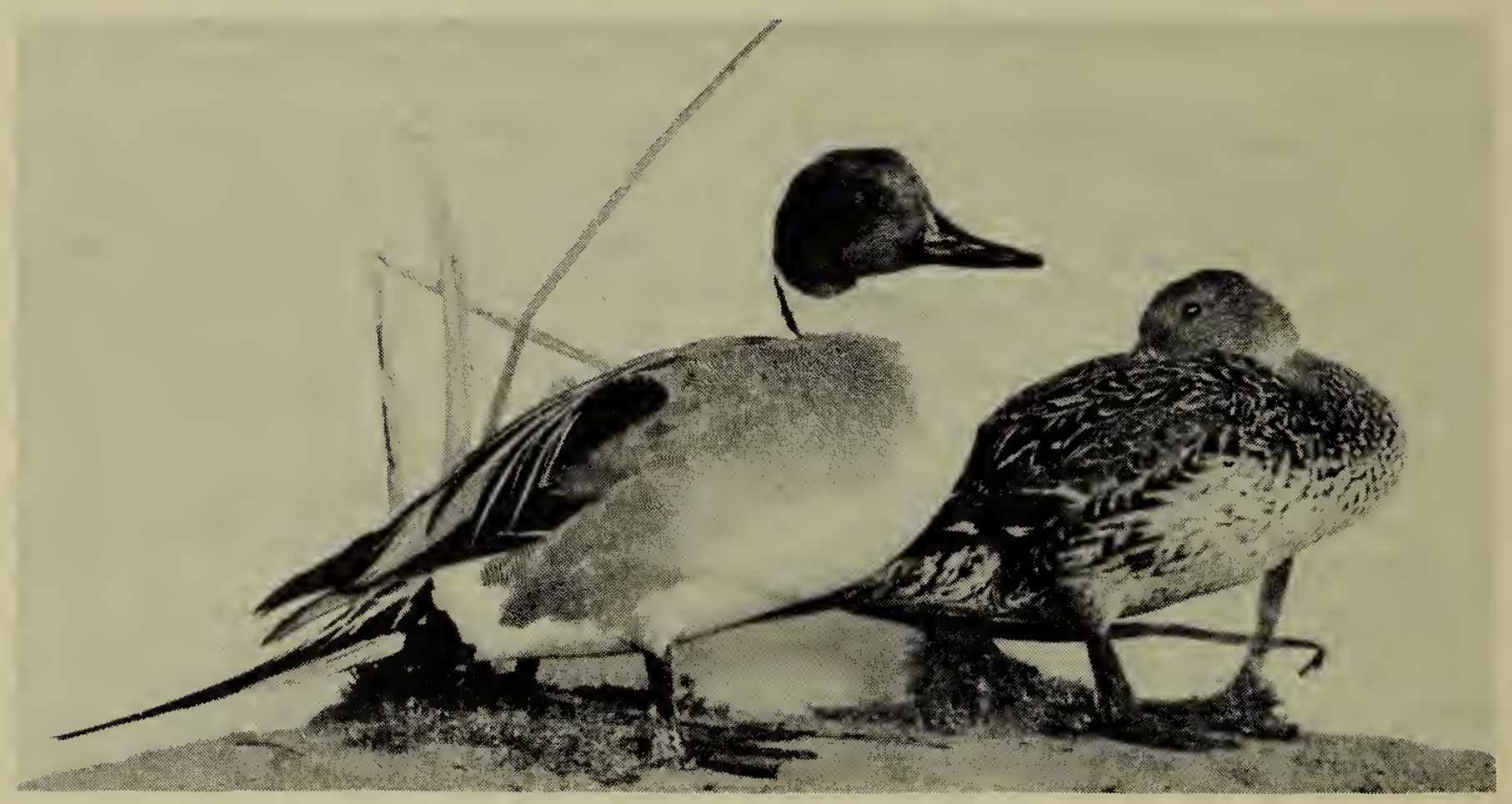

Pintail Ducks-male and female.

This picture of a pair of Pintail Ducks is only one of the numerous displays which you will see when you visit the Provincial Museum, at Regina. Every bird and animal found in Saskatchewan is on display, most of them backed by natural habitat scenes and lifelike murals whose artistic excellence and beauty is unequaled anywhere in Canada.

It is expected that in the near future the museum will have a new home, and that its priceless displays will be housed in a new and suitable building, to be erected near the north-west corner of Wascana Park, where College Avenue meets Albert Street.

\section{The New Museum}

Elizabeth Cruickshank

How thrilling to know that the new museum is at last to be a reality. How fitting to commemorate Saskatchewan's Golden Anniversary to have its natural history preserved and on view in an adequate building, conveniently located.

What a force for education it can be, for native and tourist to have graphically presented the natural resources of the province, its flora and fauna, geology and minerology, as well as its history.

Here will be a monument to the faith and courage of our pioneers and to those who followed them to develop this prairie province.

\section{Is There a Blue Jay in Your School?}

During the month of February a circular letter was sent by the Saskatchewan Department of Education to every school in the province, recommending the "Blue Jay" as a useful reference book in the field of natural science, for teachers and students.

Did you know that money from the provincial school library grant may be used for purchasing the subscription? The "Blue Jay" is already a quarterly visitor to many of our schools.

Will each member of the Society urge that the trustees of tre school in their district provide a copy or two of each issue for the use of the boys and girls there. 